\title{
Analyze the effect of phosphorus on the mechanical properties and microstructure on cast iron
}

\author{
Achmad Sambas ${ }^{1, *}$, Ananto Gamawan ${ }^{1}$ and Sophiadi Gunara ${ }^{1}$ \\ ${ }^{1}$ Bandung State Polytechnic for Manufacturing, 40135 Bandung, Indonesia
}

\begin{abstract}
Cast Iron FC250 with phosphorus alloy is used as electrode connector in the aluminum electrolysis process at PT. Indonesia Asahan Aluminium (Inalum), that is used to connect the rod with carbon anode. It will be crushed after the carbon anode dimension is reduced, that takes approximately 30 days. In order to make crushing process easier, phosphorus alloy then added into such FC250. The objective of the study is determining phosphorus effect on FC 250. The methodology consists of determine the test specimens, initiate such specimen of casting by varying the amount of phosphorus percentage of $0.3 \%, 0.5 \%, 0.7 \%$ and $0.9 \%$, then perform mechanical testing and microstructure observation on each specimen. The result is, as the percentage of phosphorus in FC 250 increased, so its hardness value whereas the value of the tensile strength even decreased. Form the microstructure point of view, the "steadit" increased as well in line with the rise of phosphorus.
\end{abstract}

\section{Background}

Gray cast iron is a material that is widely used in industry because it has several advantages, including; easy to pour, easy machining process, is able to dampen vibrations well, the strength is high enough and the price is relatively cheap. FC 250 is a gray cast iron with lamellar graphite which has a minimum tensile strength of 250 $\mathrm{MPa}$. The content of the alloy material in FC 250 , among others; Carbon ( C ) $3.4 \%$, silicon ( $\mathrm{Si}$ ) $2.0 \%$ and phosphorus $(\mathrm{P})$ 0.1-0.5 \% , and the addition of manganese ( $\mathrm{Mn}$ ) depending on the desired microstructure. Manganese $0.1 \%$, resulting in ferritic gray cast iron and manganese of $1.2 \%$, resulting in a pearlite gray cast iron. Phosphorus (up $0.5 \%$ ) which markedly embrittles the iron and increases its hardness by 30-40 points Brinell for $1 \%$ phosphorus addition[1]. Phosphide eutectic or steadit, occurs in two distinct forms in cast irons with more than $0,06 \%$ phosphorus. The pseudo-binary form is the normal form, consisting of ferrite and iron-phosphide (Fe3P). [2]

\footnotetext{
* Corresponding author: sambas.achmad@gmail.com
} 
One application of the material FC 250 with phosphorus alloys are widely used as an electrode connector on the manufacture of aluminium electrolysis process in PT. Indonesia Asahan Aluminium ( Inalum ). In its application, the electrode connector is used to connect between the carbon anode rod. Electrode connector will be broken after consumable carbon anode (approximately 30 days).

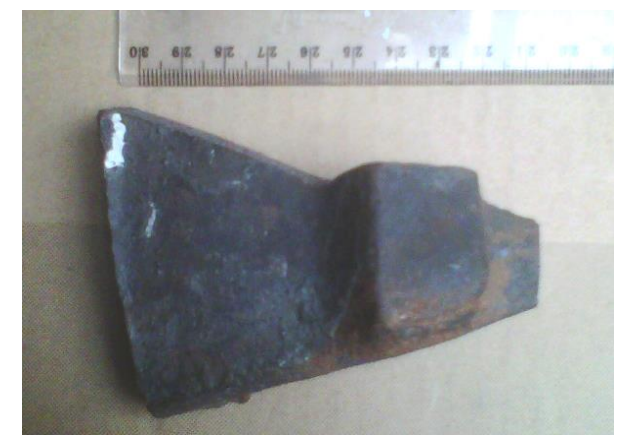

Fig. 1. The electrode connector.

Problems associated with the above background, is as follows : Why materials FC 250 given phosphorus alloys. How the influence of phosphorus on the material FC 250 on mechanical properties and microstructure. The goals to be achieved in this research is to know the effect of phosphorus on the material FC 250 on mechanical properties and microstructure. The expected benefits of this research is the application of appropriate materials for working condition.

\section{Methods}

The methodology consists of determine the test specimens, initiate such specimens of casting by varying the amount of phosphorus percentage of $0.3 \%, 0.5 \%, 0.7 \%$ and $0.9 \%$, then perform mechanical testing and microstructure observation on each specimen. Hardness test was performed using the Brinell method refers to the standard JIS Z 2243 For materials FC 250 is recommended to use this method because of the indenter used is the diameter of $10 \mathrm{~mm}$.

\subsection{Chemical Composition}

To support this research, the data analysis are taken directly from the electrode connector used in the PT. INALUM . Analysis performed on fractional electrode connector that has been unused. Further testing of chemical composition to obtain data on the composition as in Table 1. below.

Table 1. Electrode connector chemical composition by OES spectrometry.

\begin{tabular}{|c|c|c|c|c|c|c|}
\hline $\begin{array}{c}\text { Chemical } \\
\text { composition }\end{array}$ & $\begin{array}{c}\mathbf{C} \\
\mathbf{\%}\end{array}$ & $\begin{array}{c}\mathbf{S i} \\
\mathbf{\%}\end{array}$ & $\begin{array}{c}\mathbf{M n} \\
\mathbf{\%}\end{array}$ & $\begin{array}{c}\mathbf{S} \\
\mathbf{\%}\end{array}$ & $\begin{array}{c}\mathbf{P} \\
\mathbf{\%}\end{array}$ & $\begin{array}{c}\mathbf{C r} \\
\mathbf{\%}\end{array}$ \\
\hline amount & 3.2 & 1.4 & 0.73 & 0.13 & 0.7 & 0.0 \\
\hline
\end{tabular}




\subsection{Making of specimen test}

Making the specimen are using lathe and saw machine, whereas the sequence of metal casting process begins with pattern, mold making, alloying and melting [3]. Phosphorus modifications done in the pouring ladle, then poured into the mold. Determination of test specimens for hardness test refers to a tensile test specimen of JIS Z 2201 standard. Figure 2. shows the scheme of phosphorus into the mold test sa]
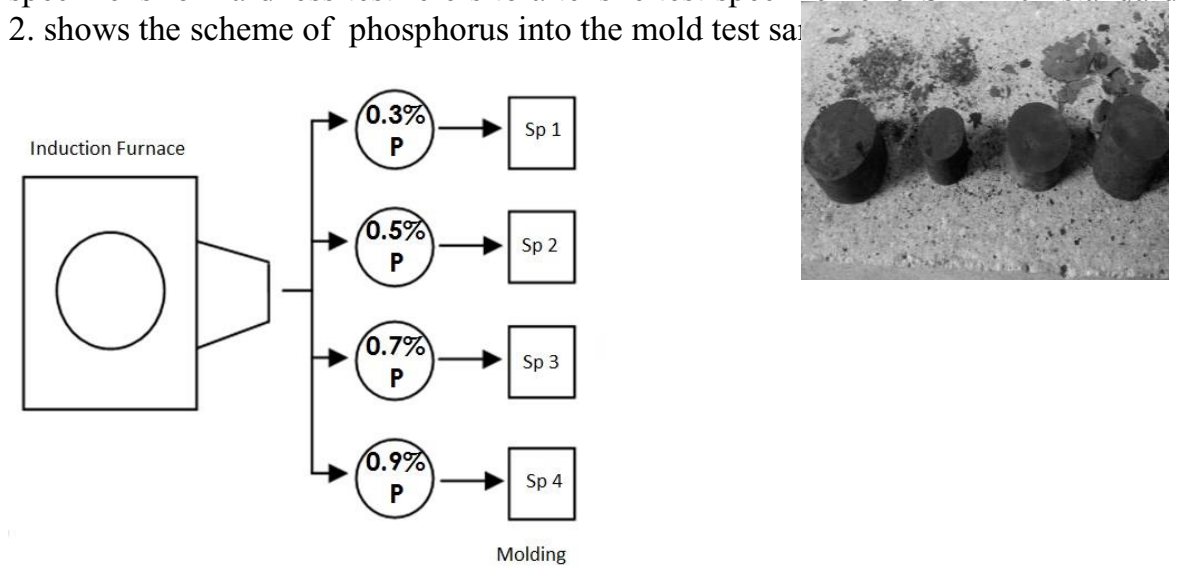

Fig. 2. Scheme of phosphorus into the molding.

\subsection{Material testing}

Tests performed included; composition test, microstructure, hardness, and tensile test. The discussion will be explained as follows:

The test specimen to test the composition of the cast iron material must be done through rapid cooling. It aims to prevent the formation of graphite in this testing is avoided existence. The test specimen is a cylinder with a diameter of $40 \mathrm{~mm}$ and $10 \mathrm{~mm}$ thick. Then do the grinding and polishing. Having obtained the flat field, then tested using the tool spectrometry.

Hardness test specimen took part stems from the tensile test specimens. Brinell hardness test using standard JIS Z 2243. Each specimen with different percentage variation is made of 3 pieces hardness test specimen. This is because the hardness causing penetration testing is quite extensive. Thus, the specimens will be used for one-time penetration. Tensile test specimens used is based on the standard JIS Z 2201 type $8 \mathrm{C}$. The specimens were taken from the test rod with a diameter of $30 \mathrm{~mm}$, then formed into a diameter of $20 \mathrm{~mm}$.

Microscopic observations were performed by optical microscope with magnification of $100 \mathrm{x}$ and 500x, and performed at the centre and edge of the specimen. Figure 5. shows the observed microstructure. Microstructure testing is performed to determine the phase configuration that occurs.

\section{Results}




\subsection{Results of Chemical Composition Characterization}

Spectrometry testing aims to determine the amount of chemical elements. The elemental composition that is using OES spectrometry shown in Table 2. below.

Table 2. chemical composition.

\begin{tabular}{|c|c|c|l|l|l|}
\hline Unsur & $\mathbf{C} \%$ & Si \% & Mn\% & S \% & P \% \\
\hline Spesimen 1 & 3.21 & 1.60 & 0.66 & 0.02 & 0.42 \\
\hline Spesimen 2 & 3.24 & 1.56 & 0.66 & 0.02 & 0.81 \\
\hline Spesimen 3 & 3.12 & 1.54 & 0.68 & 0.02 & 1.06 \\
\hline Spesimen 4 & 3.27 & 1.54 & 0.70 & 0.01 & 1.12 \\
\hline
\end{tabular}

Based on the above table, the percentage of phosphorus ( $\mathrm{P}$ ) does not match the target. This may happen due to several possibilities, among others : The content / purity of $\mathrm{Fe}-\mathrm{P}$ alloy material which is estimated to be $26 \%$ higher than that. At the time of tapping fluid volume issued less than $12 \mathrm{~kg}$. This occurs because the tapping process is done manually.

\subsection{The Results of Mechanical Testing Characterization}

Hardness test was performed using the Brinell method refers to the standard JIS Z 2243 For materials FC 250 is recommended to use this method because of the indenter used is the diameter of $10 \mathrm{~mm}$, so it will not be disturbed by graphite contained in the microstructure FC 250. Based on the above data it can be concluded that the value of hardness using Brinell hardness test has a rising graph of the percentage of phosphorus $0,42 \%, 0.81 \%, 1.06$ and $1.12 \% \%$.

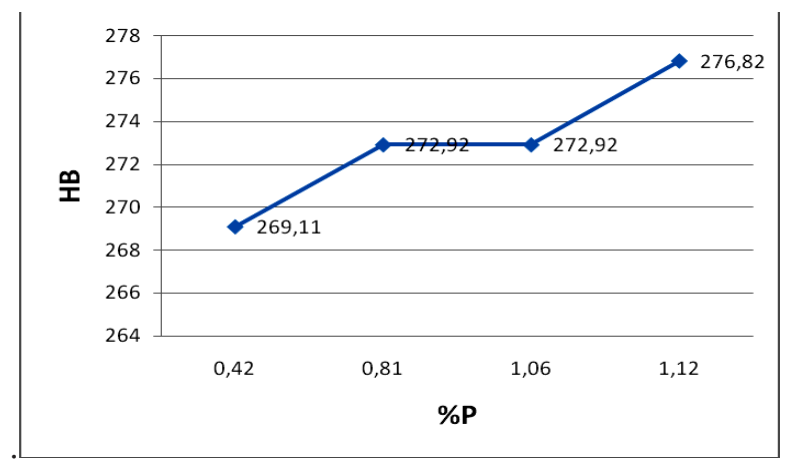

Fig. 3. The curve of specimen hardness value with various phosphor percentage.

The tensile testing process is based on the JIS Z 2201. standard. Figure 5 shows the curve of tensile test results. In the chart above can be seen that the tensile strength values have a declining graph of the percentage of phosphorus $0,42 \%, 0.81 \%, 1.06$ and $1.12 \%$ $\%$. It is inversely proportional to the hardness value using methods a Brinell.

Based on the reference that is JIS G 5501 (1995) [6], in line with the increase in tensile strength values, it will be followed by a rise in the value of hardness. Seen, along with the increase in the percentage of phosphorus followed by the percentage increase in steadit. 
For more convincing analysis, hardness testing using another method that Rockwell B Hardness ( ASTM E 18 ) and micro Vickers ( ASTM A 92 ). Based on the above data it can be seen that the value of Rockwell hardness test method has a chart that rose along with increasing the percentage of phosphorus $0,42 \%, 0.81 \%, 1.06$ and $1.12 \% \%$. This is further evidenced by the hardness testing phase using a micro Vickers method and the results of phase steadit $565 \mathrm{HV}$ is higher than $368 \mathrm{HV}$ pearlite.

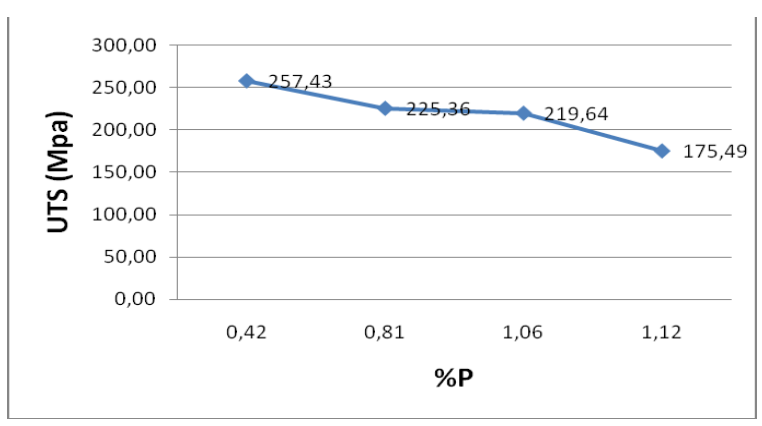

Fig. 4. The curve of tensile value with various phosphor percentage.

\subsection{The Results of Micro Structure Characterization}

Observation of microstructure on specimens is done with 500x magnification, done on side or edges of objects. Figure 6(a). shows the microstructure of the specimen 1 with the percentage of phosphorus $0,42 \%$. In the microstructure prior to etching, visible lamellar graphite with form 1 , size 4 and type A. Then the microstructure after etching using $3 \%$ nital , pearlite phase formed $96.08 \%$ and $3.92 \%$ steadit. In the composition of $0,42 \% \mathrm{P}$, steadit appear in grain boundary.

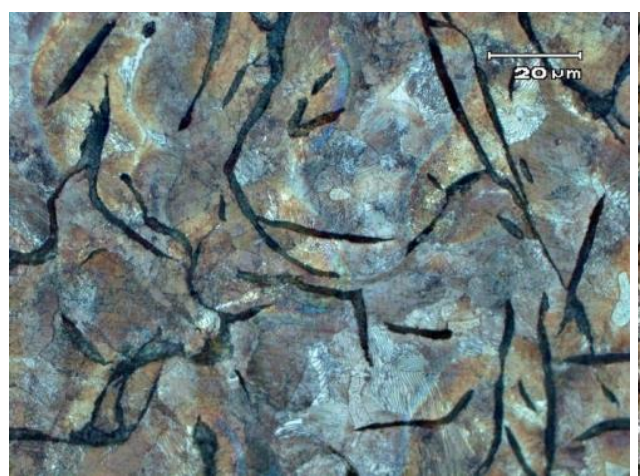

(a)

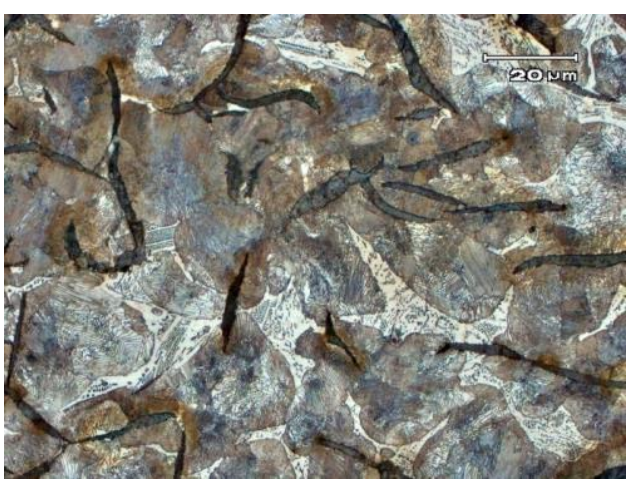

(b)

Fig. 5 . microstructure FC25, the content of $0,42 \% \mathrm{P}$, (a). the content of $0.81 \% \mathrm{P}$ (b).

Figure $6(\mathrm{~b})$. shows the microstructure of the specimen 2 with the percentage of phosphorus $0.81 \%$, visible lamellar graphite with form 1 , size 4 and type A. Then the phase formed $82.73 \%$ pearlite and $17.27 \%$ steadit. Along with the increase in the percentage of phosphorus, the percentage increased steadit phase. Steadit appear to be limited grains tend tapered shape. 
Figure 7a. shows the microstructure of the specimen with the percentage of phosphorus $1.06 \%$, visible form lamellar graphite to form 1 , size 4 and type A. Then the phase formed $81.08 \%$ pearlite and $18.92 \%$ steadit . Percentage steadit back increases with the increase in the percentage of phosphorus.

Figure $7 \mathrm{~b}$. shows the microstructure of the specimen with the percentage of phosphorus $1.12 \%$, visible form lamellar graphite to form 1 , size 4 and type A. Then the phase formed $80.63 \%$ pearlite and $19.37 \%$ steadit.

Such graphite precipitations, accompanied by pearlitic matrix and satisfactory phosphide eutectic network, are capable to ensure the best performance properties of a cylinder liner[4].

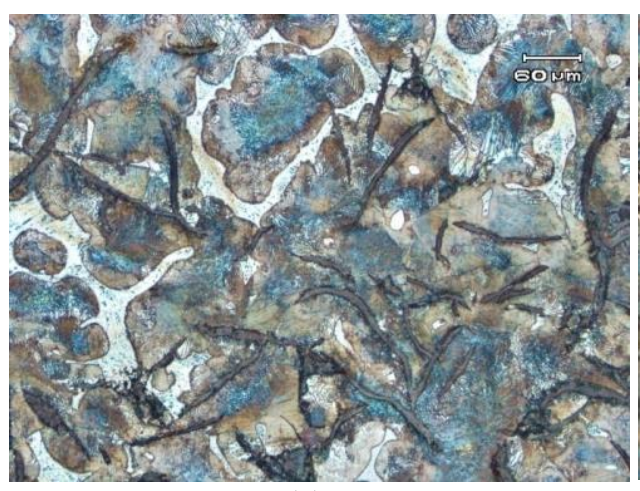

(a)

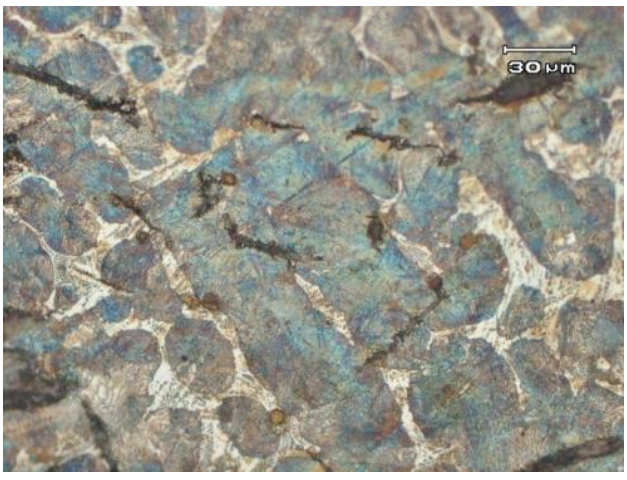

(b)

Fig. 6. Microstructure FC25, the content of $1,06 \% \mathrm{P}$, (a). the content of $1,12 \% \mathrm{P}$ (b).

\section{Conclusion}

The conclusions of the study are that, with the increase in the percentage of phosphorus in the variation of $0.42 \%, 0.81 \%, 1.06$ and $1.12 \% \%$, there is an influence on the mechanical properties and microstructure, including

- The hardness value is increase.

- The percentage of phase steadit is increase as the percentage of phosphorus.

\section{References}

1. Walton, F. Charles and Opar, Iron Castings Society, (1981)

2. Angus, H.T., Cast Iron physical and engineering properties, second edition, (1976)

3. Beeley, P., Foundry Technology, (2001)

4. A.W. Orlowich, M. Tupaj, Archives of Foundry engineering, 15 (2015)

5. Chenjunfu, Advanced Materials Research, $554-556$ (2012)

6. Japanese Standart Association, Japanesse Standards (2004)

7. Jianmin sun, Yi Zhang, Advanced Materials Research, 189-193 (2011) 